\title{
The Use of Functionalized AFM tips as Molecular Sensors in the Detection of Pesticides
}

\author{
Daiana K. Deda a, Bárbara B. S. Pereira ${ }^{\text {, Carolina C. Bueno, }}$ \\ Aline N. da Silva ${ }^{\mathrm{a}}$, Gabrielle A. Ribeiro ${ }^{\mathrm{a}}$, Adriano M. Amarante ${ }^{\mathrm{a}}$,
}

Eduardo F. Franca ${ }^{\text {b }}$ Fabio L. Leite ${ }^{\text {a* }}$

\author{
${ }^{a}$ Laboratory of Nanoneurobiophysics - LNN, Department of Physics, Chemistry and Mathematics, \\ Federal University of São Carlos - UFSCar, Sorocaba, SP, Brazil \\ ${ }^{\mathrm{b}}$ Institute of Chemistry, Federal University of Uberlândia - UFU, Uberlândia, MG, Brazil
}

Received: October 30, 2012; Revised: February 5, 2013

\begin{abstract}
Atomic force spectroscopy, a technique derived from Atomic Force Microscopy (AFM), allowed us to distinguish nonspecific and specific interactions between the acetolactate synthase enzyme (ALS) and anti-atrazine antibody biomolecules and the herbicides imazaquin, metsulfuron-methyl and atrazine. The presence of specific interactions increased the adhesion force $\left(\mathrm{F}_{\text {adh }}\right)$ between the AFM tip and the herbicides, which made the modified tip a powerful biosensor. Increases of approximately $132 \%$ and $145 \%$ in the $\mathrm{F}_{\text {adh }}$ values were observed when a tip functionalized with ALS was used to detect imazaquin and metsulfuron-methyl, respectively. The presence of specific interactions between the atrazine and the anti-atrazine antibody also caused an increase in the $\mathrm{F}_{\text {adh }}$ values (approximately $175 \%$ ) compared to those observed when using an unfunctionalized tip. The molecular modeling results obtained with the ALS enzyme suggest that the orientation of the biomolecule on the tip surface could be suitable for allowing interaction with the herbicides imazaquin and metsulfuron-methyl.
\end{abstract}

Keywords: nanobiosensors, chemical force microscopy, atomic force spectroscopy, molecular modeling

\section{Introduction}

The considerable increase in the volume of pesticides used in agriculture has resulted in a large number of disorders in and modifications to the environment ${ }^{1,2}$. Faster, cheaper and more efficient solutions to the detection and monitoring of pollutants have been gaining prominence. At the forefront of this line of research is the development of sensors using nanotechnology, which promises to deliver efficient and selective methods for the detection of pollutants ${ }^{3,4}$. In this respect, the use of atomic force microscopy (AFM) combined with chemical force microscopy (CFM) and Atomic Force Spectroscopy (AFS) can serve as an excellent alternative for the detection of agrochemicals. CFM enhances a specific intermolecular interaction, using chemically modified cantilevers, thereby selectively probing surface-functional groups of interest ${ }^{5}$. AFS measures the indentation response of the cantilevers as a function of the interaction (adhesion force) between the cantilever and the surface analyzed ${ }^{6}$.

In recent years, the use of chemically modified AFM tips as biosensors has become popular in monitoring a large number of analytes and has enabled advances in several areas, such as biological ${ }^{7,8}$ and materials science ${ }^{9}$, the detection and control of pollutants (especially herbicides $)^{10,11}$, and medicine ${ }^{12}$. Chemical functionalization gives the tips selectivity and sensitivity to interactions at the

*e-mail: fabioleite@ufscar.br molecular level. Moreover, it allows for analysis of the extent of these interactions, which exhibit variable magnitudes for different molecular groups, and enable the detailed mapping of surface chemistry with nanoscale resolution ${ }^{5}$. In many cases, functionalization occurs via the use of an active biological component, which is able to specifically bind to certain substrates. This mimicry of biological systems, i.e., by the development of sensors that act through specific interactions similar to the antibody-antigen or key-lock mechanism, has given rise to so-called biosensors or nanobiosensors ${ }^{10}$. The interactions between an AFM tip and molecules result in a force curve, which describes the extent to which the cantilever is displaced due to the surface tension generated in response to changes in the free energy of the tip surface ${ }^{6}$. Force curves provide valuable information about the properties of materials, such as elasticity, hardness, Hamaker constant, adhesion, and surface charge density ${ }^{13,6}$.

Molecular modeling (MM) techniques may prove to be important in the development of biosensors. MM systems are equipped with powerful tools for building, viewing, analyzing, and storing models of complex molecular systems that assist in the interpretation of the relationship between structure and biological activity. In the specific case of pesticide detection using CFM, molecular modeling methods can be used to evaluate the effect of a solvent on the structural dynamics and the binding energy involved in the enzyme/antibody-pesticide interaction process ${ }^{14}$. 
This paper presents the development of nanobiosensors based on chemically modified AFM tips for herbicide detection. These nanobiosensors, which have been chemically modified with enzymes and antibodies, are able to detect herbicides at low concentrations. Detection is made possible by the formation of specific interactions between specific biomolecules and the target herbicides, which confers selectivity and sensitivity to the nanobiosensor.

\section{Experimental Procedures}

\subsection{Atomic force spectroscopy}

Force spectroscopy experiments were performed using a Multimode-VS (Bruker) atomic force microscope equipped with the PicoForce software package (dedicated to force spectroscopy). The AFM tips that were used to generate the force curves were composed of silicon nitride (V-shaped, Veeco model NP-10). Each one of the three AFM tips was subjected to a calibration procedure based on the method of thermal noise before use ${ }^{15}$. Calibration values were obtained to ensure the sensitivity of the cantilever (on a silicon substrate). After the functionalization process, only small variations in the spring constants were observed and were considered negligible. Force curves were obtained at $18 \pm 3{ }^{\circ} \mathrm{C}$ and at a relative humidity between $30 \%$ and $40 \%$ using a single tip (functionalized or unfunctionalized) in the detection of each herbicide. The adhesion force values were obtained from the force curves, which were collected in contact mode. The contact force used was too low to avoid sample carryover.

\subsection{Chemical force microscopy}

The procedure used to functionalize the cantilevers (and tips) and substrates (Mica Muscovita) was adapted from a previously described method ${ }^{16}$. After the cantilevers and substrates were cleaned using Bioforce $240 \mathrm{~nm}$ Procleaner, UV PC.220, the functionalization process was initiated by the gaseous evaporation of 3-aminopropyltriethoxysilane (APTES) in the presence of triethylamine (volatile compounds), both commercial solutions $(98.0 \%$ and $99.5 \%$, respectively). After this procedure, the cantilevers and a mica substrate were coated with glutaraldehyde $\left(1 \times 10^{-3} \mathrm{M}\right)$ to form self-assembled monolayers (SAMs) that terminated in strategic functional groups to promote the proper orientation of the active sites of the bioligand and enable its interaction with the target molecule. Then, each substrate was functionalized with one herbicide (imazaquin, metsulfuron-methyl, and atrazine) by the addition of $50 \mu \mathrm{L}$ of an aqueous solution $\left(1 \times 10^{-3} \mathrm{M}\right)$ of the herbicide. The functionalization of the tips with the biomolecules is described below. All reagents employed in the functionalization process, except for the biomolecules, were purchased from Sigma.

\subsubsection{Enzymes}

Recombinant acetolactate synthase (ALS) was kindly provided by Dr. Tsutomu Shimizu from the Life Science Research Institute, Shizuwoka, Japan. After functionalization with glutaraldehyde, approximately $30 \mu \mathrm{L}$ of crude extract containing the ALS enzyme was coated on the two tips used to detect the herbicides imazaquin and metsulfuron-methyl.

\subsubsection{Antibody}

The anti-atrazine antibody (Lifespan Biosciences) was diluted approximately 1000- fold according to the manufacturer's suggested procedure. The antibody was diluted in a solution that contained $70 \%$ PBS, $3 \%$ BSA, and $30 \%$ glycerol (all from Sigma) and was subsequently stored at $-20{ }^{\circ} \mathrm{C}$ in small aliquots. The nanobiosensor used for atrazine detection was created by functionalizing a tip with $30 \mu \mathrm{L}$ of the anti-atrazine antibody solution, following functionalization with glutaraldehyde.

\subsection{Molecular modeling}

Computational molecular modeling of the AFM tip was performed using the GROMACS 5.4.5, APBS 1.4.0, MOPAC2009, Swiss-PdbViewer 4.0.1, Jmol 12.0.31, and VMD 1.9.1 software packages. Initially, a unit cell of silicon nitride was created and replicated using the software program VMD 1.9.1. Then, the APTES and glutaraldehyde molecules were added, and finally, the enzyme ALS was added based on data from the RCSB Protein Data Bank (RCSB PDB). A total of 111,616 particles were used in the system.

\section{Results and Discussion}

Using force curves, the adhesion force between two surfaces or molecules, or the force required to break the interaction between them, can be measured ${ }^{17}$. Studies were and are being developed by our research group using AFS to achieve the detection of herbicides such as metsulfuron-methyl, imazaquin, and atrazine through their interactions with biomolecules, such as enzymes and antibodies. Our studies indicate that detection is possible due to the presence of specific interactions between the nanobiosensors and the target herbicides.

The detection of enzymatic inhibitor herbicides such as metsulfuron-methyl and imazaquin is achieved through the functionalization of an AFM tip with the enzyme acetolactate synthase (ALS) ${ }^{18}$. Figure 1 presents a scheme that illustrates an AFM in operation and demonstrates the chemical interactions that occur between the tip and the substrate. The inset of Figure 1 shows the molecular modeling of the AFM tip surface functionalized with the enzyme ALS. MM techniques may provide important information about the functionalization and detection processes of biosensors. Enzymes are modeled in scale, which highlights their secondary structures, with cofactors depicted as green sticks and ions as balls represented out of scale. Attached to the tip surface by organic molecules (APTES and glutaraldehyde) represented by colored sticks, the ALS enzyme remains active and makes the surface of the tip as a whole a specific nanobiosensor for the detection of the herbicides imazaquin and metsulfuron-methyl. In this case, the formation of specific interactions depends primarily on the appropriate orientation of the biomolecule on the tip, and MM results show that there are two active sites on ALS enzyme accessible for interaction with the substrate (herbicides). In addition, molecular modeling techniques could provide information related to the energy involved in the interaction between the biomolecule and the herbicide, 
as well as predict the number of biomolecules present on the surface of the tip and how many interact with the molecules of herbicide as the tip approaches the substrate. Preliminary results indicate that there are at most nine biomolecules that are present on the surface of a tip with a radius of $20 \mathrm{~nm}$ (equivalent to the radius of the tips used in the experiments) and interact with the herbicide molecules. Studies are currently being carried out to determine the theoretical force required to disrupt the interaction between the herbicides imazaquin and metsulfuron-methyl and the ALS enzyme. Thus, it will be possible to determine the influence of other forces derived from non-specific interactions, such as capillary forces, by comparing the theoretical and experimental values of the adhesion force.
Figure 2 shows the variation in the adhesion force measured between the AFM tip and the substrates contaminated with imazaquin and metsulfuron-methyl. The average values of the adhesion force, obtained from the analysis of 30 force curves performed at a single point on three distinct substrates modified with imazaquin, were measured using an unfunctionalized AFM tip (Figure 2a) and a tip functionalized with the ALS enzyme (Figure $2 b$ ). The average values of the adhesion force were $18 \pm 2 \mathrm{nN}$ and $40 \pm 4 \mathrm{nN}$ for the unfunctionalized and functionalized AFM tips, respectively. We observed an increase of $132 \%$ in the adhesion force measured with a functionalized tip relative to that measured with an unfunctionalized tip. This suggests the presence of a specific interaction between the enzyme and the herbicide imazaquin. Furthermore, it can

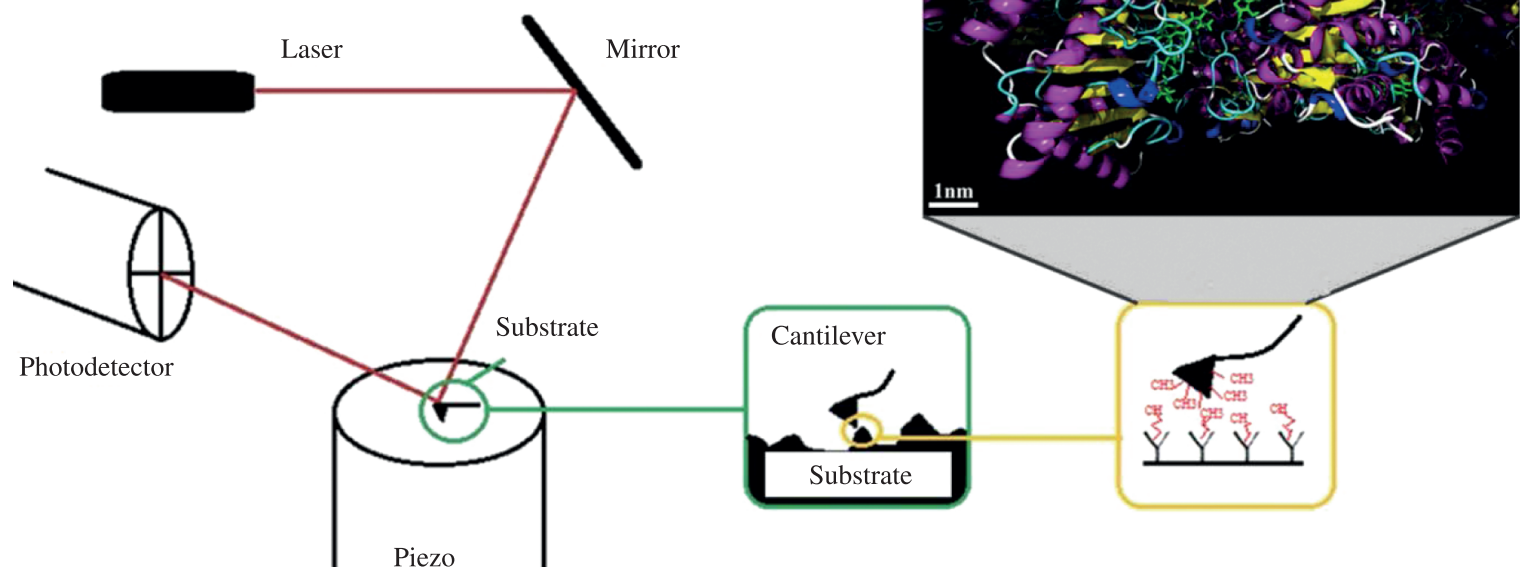

Figure 1. Scheme illustrating an atomic force microscope in contact-mode operation and details regarding the chemical interactions between the tip and the substrate. Inset: Computational molecular modeling shows the surface of the AFM tip functionalized with the ALS enzyme (visualization by VMD 1.9.1 software).

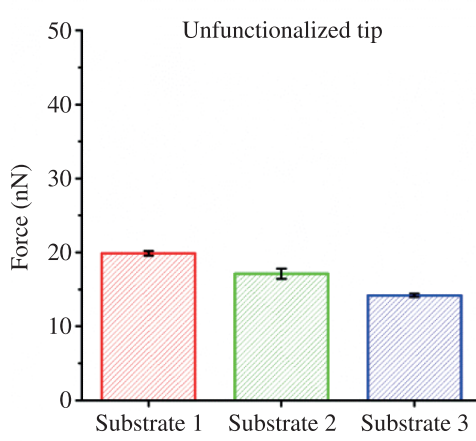

(a)

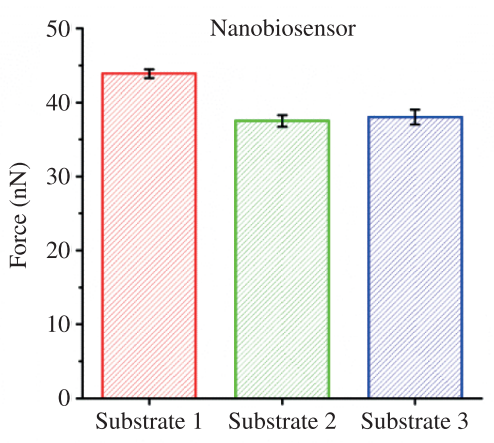

(b)

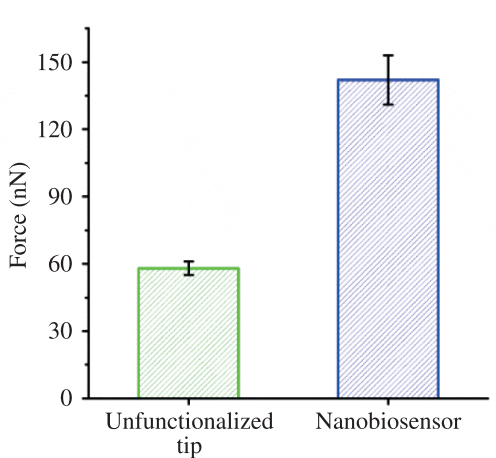

(c)

Figure 2. Comparative graphs of the average adhesion force values $(\mathrm{n}=30)$ measured using (a) unfunctionalized $\left(\right.$ sensibility $\left.=129.7 \mathrm{~nm} . \mathrm{V}^{-1}\right)$ and (b) functionalized (sensibility $=37.25 \mathrm{~nm} \cdot \mathrm{V}^{-1}$ ) AFM tips on three different substrates contaminated with the herbicide imazaquin $\left(\mathrm{K}=0.20 \mathrm{~N} \cdot \mathrm{m}^{-1}\right)$. (c) Average adhesion force values obtained from 5000 force curves measured with an unfunctionalized (sensibility $=102,1 \mathrm{~nm} \cdot \mathrm{V}^{-1}$ ) tip and a nanobiosensor $\left(\right.$ sensibility $=65,45 \mathrm{~nm} \cdot \mathrm{V}^{-1}$ ) on substrates contaminated with the herbicide metsulfuron-methyl $\left(\mathrm{K}=0.10 \mathrm{~N} \cdot \mathrm{m}^{-1}\right)$. 


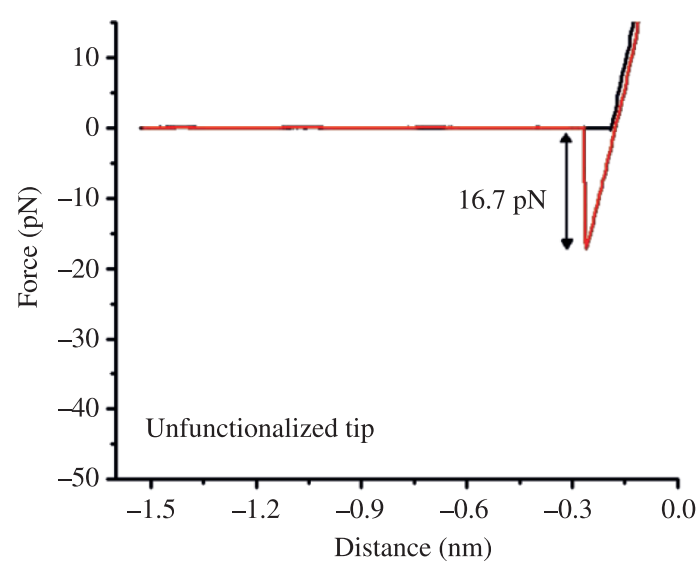

(a)

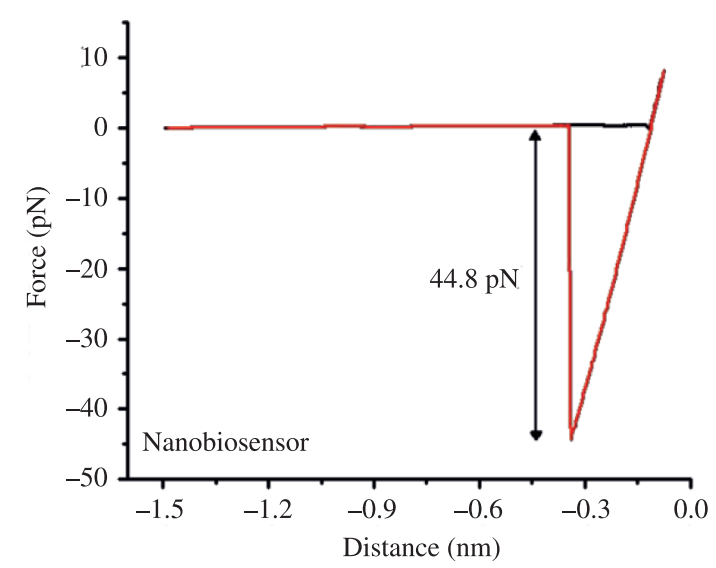

(b)

Figure 3. Typical force curves obtained using (a) an unfunctionalized tip and (b) a tip functionalized with anti-atrazine antibody (nanobiosensor) for the detection of the herbicide atrazine $\left(\mathrm{K}=0.06 \mathrm{~N} . \mathrm{m}^{-1}\right)$.

be seen that there was only a small variation in the adhesion force values obtained on different substrates, which indicates the reproducibility of the method and, in particular, of the functionalization process.

The presence of specific interactions also allowed for the detection of metsulfuron-methyl. In the graph shown in Figure 2c, obtained from the analysis of 5000 force curves distributed over an area of $50 \mu^{2}$, the adhesion force values obtained with an unfunctionalized tip ranged from 52 to $61 \mathrm{pN}$, with an average value of $58 \mathrm{pN}$. The adhesion force values measured with the functionalized tip were higher, varying from 128 to $156 \mathrm{pN}$, with an average value of $142 \mathrm{pN}$. These results indicate that a specific interaction indeed occurred between the herbicide metsulfuron-methyl and the enzyme ALS. This interaction with the herbicides occurs because they inhibit the ALS enzyme in vivo, and this inhibition depends on strong recognition and binding to attract them. The unfunctionalized tip contains no ligand that interacts with the herbicide, and the adhesion force between the two molecules is therefore lower and occurs essentially by van der Waals interactions or by electrostatic, hydrophilic and hydrophobic interactions, among others. It is noteworthy that the adhesion force between the unfunctionalized tip and unfunctionalized substrate was approximately $8 \% \pm 2 \%$ of the value obtained using the unfunctionalized tips and the substrates contaminated with the herbicides.

Small deviations were observed in the results presented in Figure 2 due to the high specificity of the nanobiosensor. Additionally, the deviation observed in the 5000 measurements of the adhesion force between the ALS enzyme and metsulfuron-methyl herbicide (Figure 2c) was considered to be satisfactory (lower than $8 \%$ ) because it provides an indication of the integrity of the nanobiosensor, which retained its detection capacity even after being used to generate numerous force curves.

Similar to enzymes, antibodies (anti-pesticides) are also considered excellent alternatives for the development of biosensors. The use of antibodies is considered very promising because of the high degree of selectivity and specificity of antibody-antigen binding. The use of cantilevers functionalized with antibodies specific to some herbicides has been previously described, and the importance of the specific interactions in the detection efficiency of these nanosensors has also been reported ${ }^{10,11,19}$. Several methods involve the use of anti-atrazine antibodies in biosensors for the detection of herbicides ${ }^{11,20}$. However, there are no reports of the detection of herbicides through the analysis of adhesion force using this antibody; thus, in this paper, we also describe the efficiency of a nanobiosensor functionalized with an anti-atrazine antibody for the detection of atrazine. Figure 3 shows typical force curves obtained with unfunctionalized (Figure 3a) and functionalized tips (Figure $3 \mathrm{~b}$ ). The tip functionalized with the antibody specific to the atrazine herbicide was promising as a biosensor because of the specific binding between the antibody and atrazine, which generated an increase in the adhesion force of approximately $175 \%$ compared to the force measured with the unfunctionalized tip. Adhesion forces of 16 and $44 \mathrm{pN}$ were measured using the unfunctionalized and functionalized tips, respectively.

The results presented in this paper illustrate the importance of the chemical modification/functionalization of tips, which is made possible by the formation of specific interactions with the substrate (herbicides). The methodology employed resulted in small variations in the measured adhesion force values, which makes this method promising for the qualitative determination of imazaquin, metsulfuron-methyl and atrazine.

\section{Conclusions}

We have described the development of nanobiosensors based on AFM tips functionalized with biomolecules and their applications in pesticide detection. Analysis of the adhesion force values demonstrated a substantial difference in performance between the functionalized and the unfunctionalized AFM tips in response to substrates contaminated with herbicides. High adhesion values were observed between the tip functionalized with the ALS 
enzyme or anti-atrazine antibody (biosensors) and substrates modified with herbicides. These high adhesion values are due to specific interactions between the biomolecules adhered to the tips and the herbicides. Thus, the combination of CFM and AFS enabled the detection of imazaquin, metsulfuron-methyl and atrazine on a molecular scale, which makes this technique promising for the qualitative evaluation of these pesticides.

\section{References}

1. Goodland R. Environmental sustainability in agriculture: diet matters. Ecological Economics. 1997; 23(3):189-200. http:// dx.doi.org/10.1016/S0921-8009(97)00579-X

2. Nikoloff N, Soloneski S and Larramendy ML. Genotoxic and cytotoxic evaluation of the herbicide flurochloridone on Chinese hamster ovary (CHO-K1) cells. Toxicology in Vitro. 2012; 26(1):157-163. PMid:22080090. http://dx.doi. org/10.1016/j.tiv.2011.10.015

3. Boro RC, Kaushal J, Nangia Y, Wangoo N, Bhasin A and Suri CR. Gold nanoparticles catalyzed chemiluminescence immunoassay for detection of herbicide 2,4-dichlorophenoxyacetic acid. Analyst. 2011; 136(10):2125-2130. PMid:21455533. http:// dx.doi.org/10.1039/c0an00810a

4. Liu R, Guan G, Wang S and Zhang Z. Core-shell nanostructured molecular imprinting fluorescent chemosensor for selective detection of atrazine herbicide. Analyst. 2011; 136(1):184-190. PMid:20886153. http://dx.doi.org/10.1039/c0an00447b

5. Fritz J. Cantilever biosensors. Analyst. 2008; 133(7):855-863. PMid:18575634. http://dx.doi.org/10.1039/b718174d

6. Garcia R and Perez R. Dynamic atomic force microscopy methods. Surface Science Reports. 2002; 47(6-8):197-301. http://dx.doi.org/10.1016/S0167-5729(02)00077-8

7. Kim H, Park JH, Cho IH, Kim SK, Paek SH and Lee H. Selective immobilization of proteins on gold dot arrays and characterization using chemical force microscopy. Journal of Colloid and Interface Science. 2009; 334(2):161-166. PMid:19406421. http://dx.doi.org/10.1016/j.jcis.2009.03.082

8. Costa LT, Vilani C, Peripolli S, Stavale F, Legnani C and Achete CA. Direct immobilization of avidin protein on AFM tip functionalized by acrylic acid vapor at RF plasma. Journal of Molecular Recognition. 2012; 25(5):256-261. PMid:22528186. http://dx.doi.org/10.1002/jmr.2189

9. Fujihira M, Furugori M, Akiba U and Tani Y. Study of microcontact printed patterns by chemical force microscopy. Ultramicroscopy. 2001; 86(1-2):75-83. http://dx.doi. org/10.1016/S0304-3991(00)00109-1

10. Alvarez M, Calle A, Tamayo J, Lechuga LM, Abad A and Montoya A. Development of nanomechanical biosensors for detection of the pesticide DDT. Biosensors \& Bioelectronics. 2003; 18(5-6):649-653. http://dx.doi. org/10.1016/S0956-5663(03)00035-6

\section{Acknowledgements}

The authors acknowledge FAPESP (Proc. 2007/05089-9 Proc. 2010/04599-6; 2009/09120-3), CAPES, CNPq (Proc. 483303/2011-9) and nBioNet for their financial support. The authors gratefully acknowledge the efforts of Dr. Vadim Viviani and Dr. Rogilene Aparecida Prado (Federal University of São Carlos) for the production and assays of the ALS enzyme.

11. Suri CR, Kaur J, Gandhi S and Shekhawat GS. Label-free ultra-sensitive detection of atrazine based on nanomechanics. Nanotechnology. 2008; 19(23):1-6.

12. Ilic B, Yang Y and Craighead HG. Virus detection using nanoelectromechanical devices. Applied Physics Letters. 2004; 85(13):2604-2606. http://dx.doi. org/10.1063/1.1794378

13. Leite FL, Bueno CC, Da Róz AL, Ziemath EC and Oliveira Junior ON. Theoretical Models for Surface Forces and Adhesion and Their Measurement Using Atomic Force Microscopy. International Journal of Molecular Sciences. 2012; 13:1277312856. PMid:23202925 PMCid:3497299. http://dx.doi. org/10.3390/ijms 131012773

14. Franca EF, Leite FL, Cunha RA, Oliveira ON and Freitas LCG. Designing an enzyme-based nanobiosensor using molecular modeling techniques. Physical Chemistry Chemical Physics. 2011; 13(19):8894-8899. PMid:21455530. http:// dx.doi.org/10.1039/c1cp20393b

15. Hutter JL and Bechhoefer J. Calibration of atomicforce microscope tips. Review of Scientific Instruments. 1993; 64(7):1868-1873. http://dx.doi. org/10.1063/1.1143970

16. Fiorini M, McKendry R, Cooper MA, Rayment T and Abell C. Chemical force microscopy with active enzymes. Biophysical Journal. 2001; 80(5):2471-2476. http://dx.doi.org/10.1016/ S0006-3495(01)76215-7

17. Leite FL, Mattoso LHC, Oliveira Junior ON and Herrmann Junior PSP. The Atomic Force Spectroscopy as a Tool to Investigate Surface Forces: Basic Principles and Applications. In: Méndez-Vilas A and Díaz J. Modern Research and Educational Topics in Microscopy. Formatex; 2007. p. 747-757.

18. Kawai K, Kaku K, Izawa N, Shimizu M, Kobayashi H and Shimizu T. Herbicide sensitivities of mutated enzymes expressed from artificially generated genes of acetolactate synthase. Journal of Pesticide Science. 2008; 33(2):128-137. http://dx.doi.org/10.1584/jpestics.G07-29

19. Bache M, Taboryski R, Schmid S, Aamand J and Jakobsen $\mathrm{MH}$. Investigations on antibody binding to a microcantilever coated with a BAM pesticide residue. Nanoscale Research Letters. 2011; 6:386. PMid:21711907 PMCid:3211479. http:// dx.doi.org/10.1186/1556-276X-6-386

20. Schirhagl R, Latif U and Dickert FL. Atrazine detection based on antibody replicas. Journal of Materials Chemistry. 2011; 21(38):14594-14598. http://dx.doi. org/10.1039/c1jm11576f 